\title{
Los primeros pasos de la democracia en Venezuela bajo el prisma de la diplomacia española $(1958-1962)^{*}$
}

\author{
The first steps of democracy in Venezuela under \\ the vision of Spanish diplomacy (1958-1962)
}

\author{
Ángel Dámaso Luis León \\ ORCID iD: https://orcid.org/0000-0003-1311-9679 \\ Universidad de La Laguna, Santa Cruz de Tenerife, España
}

El proceso de cambio político propiciado en Venezuela generó incertidumbre en algunos países con estrecha relación. La transición a la democracia producida a finales de los cincuenta y el posterior proceso de construcción sus instituciones fue objeto de interés de muchos países, entre ellos, de España. En este artículo, se buscará analizar cómo es percibido ese proceso por parte de la legación diplomática española. A través de la documentación de archivo generada, se observarán las visiones y opiniones emitidas acerca de los diferentes actores que jugaban un papel importante en la política venezolana de mediados de siglo.

PAlabras ClaVE: Venezuela; transición; democracia; diplomacia española; relaciones internacionales.

The process of political change produced in Venezuela generated uncertainty in some closely related countries. The transition to democracy that took place in the late 1950s and the subsequent process of building its institutions was the object of interest in many countries, including Spain. This article will seek to analyze how this process is perceived by the Spanish diplomatic legation. Through the archival documentation generated, we will observe the visions and opinions expressed about the different actors who played an important role in Venezuelan politics of the mid-century.

KeYwords: Venezuela; Transitions; Democracy; Spanish Diplomacy; International Relations.

Copyright: (C) 2021 CSIC. Este es un artículo de acceso abierto distribuido bajo los términos de la licencia de uso y distribución Creative Commons Reconocimiento 4.0 Internacional (CC BY 4.0).

* Esta investigación forma parte del proyecto «El orden y sus desafíos en el Circuncaribe hispano, 1791-1960 (MICINN RTI2018-096761-B-I00)» y se encuentra financiada por los contratos «La Caixa/Fundación CajaCanarias-Universidad de La Laguna». 


\section{Introducción}

El proceso de construcción de un sistema democrático en Venezuela, iniciado a finales de la década de los cincuenta, no fue una tarea sencilla. La escasa tradición democrática del país, que apenas había disfrutado de tres años de tumultuosa experiencia previa a mediados del decenio anterior, el llamado Trienio Adeco (1945-1948), y la multitud de tensiones, nacionales e internacionales, que hacían tambalear la incipiente democracia, suponían un desafío constante para la cristalización de un modelo que, hasta cierto punto, se antojaba novedoso y desconocido para muchos venezolanos.

Cómo se percibe esta nueva realidad desde el punto de vista de la embajada española en Caracas, una legación realmente prolífica a la hora de trasvasar información a su gobierno, será el objetivo primordial de este estudio. Para ello, se analizará la documentación perteneciente a esta embajada que en la actualidad se encuentra conservada en el Archivo General de la Administración. La información reflejada en esta documentación será sometida a un análisis crítico, intentando verificar si lo que en ella aparece es certero o no, por lo que se deberá contrastar con otras fuentes de diversa procedencia, así como con la bibliografía preexistente. Además de ese análisis de verosimilitud, y más importante incluso que el mismo, un análisis exhaustivo y cualitativo de la documentación permitirá conocer cómo observaba la estructura de exteriores del régimen franquista la construcción de un modelo republicano y democrático en un país tan cercano culturalmente como es Venezuela.

Este tipo de estudio no es único, sino que sigue un patrón ya anticipado por otros autores. Dichos autores han tenido como objeto principal de estudio cómo la diplomacia española observa a algunos países americanos (principalmente Cuba) durante diversos segmentos del siglo $\mathrm{XX},{ }^{1}$ algunos de ellos incluso han hecho hincapié en períodos de transición o readaptación política, que son los que quizás más se ajusten al patrón a seguir. Siguiendo esa estela, el presente estudio buscará realizar un análisis similar para un proceso de readaptación institucional, en este caso, del contexto venezolano.

Una vez definido el marco geográfico, es importante remarcar la temporalidad en la que se ubica. La democracia se hace efectiva en Venezuela en el tránsito entre 1958 y 1959, en los que los gobiernos provisionales desarrollados tras la caída del régimen de Pérez Jiménez dejan paso al

1 Como una amplia muestra pueden citarse, De Paz Sánchez, 1997 y 2001; Macías Martín, 2002; Escobedo Romero, 2010; Cerrano, 2011; Cañellas Más, 2018. 
ejercicio efectivo de la soberanía popular expresada a través de las urnas. Por ello, se fijará la línea de inicio en ese año 1958, situándose a su vez el límite final en 1962. La elección de este año no se produce de manera arbitraria, sino que está generada por dos aspectos: uno de tipo institucional y otro relacionado con el contrapoder. En el primero de los casos, en el año 1962, ya se puede observar cómo la institucionalidad del régimen venezolano se ha hecho totalmente plausible. Se han producido elecciones, ejerce un presidente democráticamente electo, hay un legislativo y unos partidos fuertes y, sobre todo, hay promulgada y entrará en ejercicio una constitución que se mantendrá vigente durante casi 40 años. Desde el punto de vista del contrapoder, este año supondrá el fin de las intentonas militares para hacer caer el incipiente régimen democrático ${ }^{2}$ y se produce una readaptación del principal modelo de lucha a uno ciertamente importado.

A pesar del peso que tiene Venezuela en la región, este estudio estará centrado en política interior, en institucionalidad, al menos principalmente. Y para ello el mismo seguirá las pautas de los trabajos de autores como Hall y Taylor, ${ }^{3}$ y sobre todo, Peters. ${ }^{4}$ Analizar cómo la embajada en Caracas percibe la realidad venezolana en el encuadre internacional conllevaría sobrepasar los lógicos límites de esta publicación. Aún así, no puede entenderse la realidad interna venezolana durante este período, sin la acción directa de ciertos actores internacionales, como pueden ser la República Dominicana, los Estados Unidos (EE. UU.) y, principalmente, de Cuba. Desde esta base, la premisa de partida es que la embajada española en Caracas buscará cierta sintonía y verá con buenos ojos el desarrollo democrático en Venezuela, a pesar de ser un régimen totalmente opuesto al existente en España.

\section{El papel de la embajada española en Caracas, una clave contextual}

El peso de Caracas para España a mediados del siglo XX no era el de un país cualquiera. Más allá de la inmensa relación cultural que unía y une a Venezuela y España, en ese momento, los dos países se encontraban inmersos en un proceso migratorio masivo que llevó a multitud de españoles

2 A partir de los años sesenta se inaugura una fase de simbiosis cívico-militar y a una serie de reacomodos que llevaron a un acuerdo de larga duración entre ambos sectores. Para ampliar, véase Langue, 2006, 190-191.

3 Hall y Taylor, 1997.

4 Peters, 1999. 
a Venezuela. Varios centenares de miles (principalmente canarios, a los que posteriormente se añadirían los gallegos $)^{5}$ tejieron una relación especial entre los dos países que, sin ninguna duda, influyó en la dinámica bilateral y en la visión que España y que su estructura diplomática tenían de Venezuela. Este estudio no se centra en la dinámica migratoria, ni tampoco en las relaciones directas entre países, no excesivamente estudiadas para la Edad Contemporánea, ${ }^{6}$ pero está claro que ambos procesos incidirán en la percepción que desde la embajada se transmite a Madrid, y que será la que cuaje en el Ministerio de Asuntos Exteriores.

La mayor parte del tiempo que atañe a esta investigación coincide con el período en el que el marqués de Saavedra, Carlos Cañal y Gómez-Imaz se desempeña como embajador. El marqués de Saavedra procedía de la embajada de Uruguay, donde ocupó el cargo durante varios años hasta tomar posesión de la legación en Caracas, en mayo de 1959, ${ }^{7}$ sustituyendo al falangista de primera hora Manuel Valdés Larrañaga, ${ }^{8}$ quien habría de desempeñar el cargo en la capital venezolana entre 1954 y 1959. Durante los últimos meses de 1962, el cargo fue ostentado por Joaquín Manuel Rodríguez de Gortázar y Pastor, un diplomático que procedía de la embajada en Bolivia. ${ }^{9}$ Tampoco se puede obviar la importante figura del encargado de negocios, la cual fue detentada por personajes de importancia en el mundo de la diplomacia hispana como Ernesto Barnach-Calbó, Enrique Pérez-Hernández y José María Saro y Posada. Esta figura generó también cantidades importantes de documentación que era transmitida a Madrid.

Los miembros de esta embajada serán partícipes pasivos de un período de cierta convulsión en Venezuela y no se sentirán libres de la contienda puesto que el franquismo, en ocasiones, será identificado como un objetivo político por parte de diversos actores. Esta situación llevará a un trasvase de información constante relativa a los asuntos españoles, llegando en ocasiones a tener que tomar cartas en la actualidad política venezolana a través de reclamaciones, pero también experimentando los problemas producidos por la difícil situación en el país, como es el caso, por ejemplo, del miedo

5 Para el caso canario, véase Hernández González, 2007, 196-225; para el gallego, que se desarrolla a partir de la década de los cincuenta, Campos Álvarez, 2015.

6 La historia de las relaciones entre ambos países no ha sido excesivamente estudiada más allá del siglo XIX, para el que sí que hay varios estudios. Para el XX solo tenemos el sucinto artículo de Mondolfi Gudat (1999), y ya para gran parte de lo que llevamos de siglo XXI destaca Luis León, 2016.

7 «El nuevo embajador en Caracas», $A B C$, Madrid, 15 de mayo de 1959, 38.

8 Para una sucinta biografía de Valdés Larrañaga, puede verse Argaya Roca, 2018.

9 Boletín Oficial del Estado, núm. 190, España, 9 de agosto de 1962, p. 11202. 
a que la embajada española se sumara a otras, durante la oleada de toma de embajadas producida por sectores izquierdistas durante el año $1962 .{ }^{10}$

\section{Betancourt y los adecos encabezan el proceso.}

Las primeras elecciones democráticas de este período en Venezuela dieron un ganador incontestable: Acción Democrática (AD) y, más concretamente su líder, Rómulo Betancourt. El que estaba llamado a ser nuevo presidente del país había cosechado casi la mitad del voto, venciendo a otros dos candidatos muy fuertes, Wolfgang Larrazábal y Rafael Caldera. Esta contundente victoria en el ámbito presidencial, también fue acompañada por una victoria similar en las elecciones legislativas que se celebraron simultáneamente, y en las que el partido blanco se había impuesto con claridad al resto de competidores. ${ }^{11}$

La tradicional relación de Betancourt con Franco no hacía propiciar nada bueno. El venezolano había roto relaciones con España en su anterior mandato presidencial durante el Trienio Adeco, una decisión que justificaría a posteriori definiendo al régimen de Franco como una «excrecencia del fascismo que desgobierna Madrid». ${ }^{12}$ Pero la situación había cambiado para 1959. Venezuela no era la misma que en el año 1945 y su composición social tampoco. Más de 100.000 españoles vivían por ese entonces en el territorio y romper la vinculación política con su país de origen no era tan sencillo, sobre todo cuando la política migratoria, a partir de entonces, se iba a canalizar hacia otros derroteros. ${ }^{13}$ Tampoco el régimen de Franco se encontraba en la misma situación que al finalizar la guerra, cuando su nombre quedaba asociado a los países filofascistas del Eje. A finales de los cincuenta el régimen se encontraba mucho más aceptado internacionalmente. Además de ello, y mucho más importante aún, tanto Betancourt como el sector mayoritario de $\mathrm{AD}$ se habían vuelto más pragmáticos.

$10 \ll$ Se agrava situación delictiva Venezuela. Guerrilleros toman un pueblo. Extremistas queman dos Embajadas», Caracas, 4 de octubre de 1962, Archivo General de la Administración, Alcalá de Henares (AGA), 54/11877, Política Exterior (PE), n. 693, f. 1.

11 Obtuvo 73 de los 133 diputados y 32 de los 51 senadores. «Comparativo. Diputados al Congreso electos 1958-1998. Directos, complementarios y adicionales». Consejo Nacional Electoral $(C N E)$, Caracas, Secretaría General, Dirección de Estadísticas Electorales, División de Geografía Nacional, 5.

12 Betancourt, 1990, 48.

13 Hernández González 2007, 209-210. 
Aún así, existía cierto temor dentro del Ministerio de Exteriores a que la nueva etapa de Betancourt en el poder se pareciera a la anterior. Al parecer, la embajada en La Habana temía de Betancourt, «su capacidad de maniobra y de perturbación extendida desde hace tiempo por toda el área del Caribe». ${ }^{14}$ Esas apreciaciones también eran compartidos por un sector importante de la prensa ibérica. A finales de 1958, tras conocerse que Betancourt sería el ganador de las presidenciales, $A B C$ alertaba de que existían concomitancias entre la extrema izquierda y el nuevo presidente electo, llegando a afirmar que «Rómulo Betancourt personifica la tendencia contraria a lo que representan las Fuerzas Armadas y los sectores moderados». ${ }^{15}$

Este temor de que Betancourt tendiera hacia el extremismo estaría justificado en parte. Por un lado, es innegable el legado del Trienio Adeco, sobre todo en relación a España, y también parece de sobra comprobado que Betancourt había tenido un pasado comunista. ${ }^{16}$ Aunque no es menos cierto que la biografía del líder venezolano era un viaje casi constante hacia la socialdemocracia, y que en 1958 se situaba más en las coordenadas de otros líderes de centro-izquierda como José Figueres o Juan Bosch, que cercano a tendencias de corte comunista, de las cuales no solo se alejaba, sino que además enfrentaba. La prueba más fehaciente de ello fue la temprana firma del pacto de gobernabilidad conocido como Pacto de Puntofijo, del que estaban llamados a formar parte del primer gobierno todos los partidos excepto los comunistas. ${ }^{17}$

La realidad es que esta segunda versión de Betancourt se fue imponiendo porque su actuación fue incontestable. Betancourt se encontraba muy lejos del comunismo ${ }^{18}$ hecho que incluso le costó una división en las filas de su propio partido. Ya en noviembre de 1959, con menos de un año en el poder, el marqués de Saavedra informaba de que solo un sector de $\mathrm{AD}$, con el presidente de la República a la cabeza, se podía considerar de verdad anticomunista en el país ${ }^{19}$ y que el gobierno se encontraba en un entorno complejo con presiones tanto de sectores procomunistas como de

14 Citado en De Paz Sánchez, 1997, 98.

15 «Mayoría relativa para Betancourt», $A B C$, Madrid, 10 de diciembre de 1958, 48.

16 Caballero, 2004, 109 y ss.

17 Para ampliar, puede verse Velásquez, 1979, 219-221.

18 Un ejemplo de ello es un discurso pronunciado en Caracas el 1 de noviembre de 1960, donde afirma que «Venezuela no está dispuesta a tolerar la implantación en el país de una dictadura de tipo totalitario y fascistoide, ni de una dictadura de tipo totalitario y comunistoide», deslizando un cierto paralelismo entre ambas. Véase Betancourt, 2007, 230.

19 Telegrama cifrado urgente n. ${ }^{\circ} 115$, Caracas, 9 de noviembre de 1959, AGA, 54/11865. 
sectores derechistas que conspiraban, cada uno por su lado, para hacerlo caer. ${ }^{20}$ Dentro de ese gobierno se hacía alusión a elementos más blandos o más férreos, como es el caso de Carlos Andrés Pérez, ministro de Relaciones Interiores entre 1962 y 1963, el cual era reconocido como un hombre ubicado en la línea dura. ${ }^{21}$ Resulta curioso como si bien Saavedra establece antipatías con los comunistas, no hay atisbo de simpatías implícitas con los otros potenciales conspiradores.

La embajada se hará eco de la inestable situación en el país, de las continuas protestas y de la actuación policial. Hay una cierta sensación de escalada de acción-reacción entre los sectores juveniles izquierdistas, principalmente, y las fuerzas de seguridad del estado. La progresiva activación de los sectores juveniles llevará a momentos de franca tensión en las calles del país, principalmente de la capital, que llegarán a su punto álgido a finales de $1960 .{ }^{22}$ Dicho lo cual, la legación española no compartía la famosa tesis del «gobiernito», extendida sobre todo entre los sectores revolucionarios, no solo civiles sino también militares, que consideraban que el gobierno era débil y que caería pronto. ${ }^{23}$ Para el marqués de Saavedra, «este Presidente [de la] República que cultiva mucho [a] militares demócratas contrarios [a] Pérez Jiménez, es posible [que] logre dominar [la] crisis [en la que] se debate este país [y] cuyo curso exacto es difícil determinar por [la] complejidad [de] factores». ${ }^{24}$

En cierta medida, la embajada es presa de una cuestión que no es baladí, y es la «caraquización» de la política venezolana en ese entonces. Para principios del período democrático se produce una extrapolación del discurso de lo que ocurre en Caracas al resto del país. Esta es una simplificación en la que no solo caerá la embajada española, también lo harán los grupos revolucionarios que buscan extender una situación que no es que se limite a la capital y sus alrededores, pero que presenta un contraste entre esta y el resto del país. También caerán en ello los medios de comunicación más importantes, haciendo que trascendiera esa idea de inestabilidad generalizada, y que haya afectado incluso a la historiografía clásica, pero la realidad era más heterogénea, como muestra el masivo apoyo electoral

20 Telegrama cifrado n. ${ }^{\circ} 132$, Caracas, 11 de diciembre de 1959, AGA, 54/11865.

21 «Reunión "en la cumbre" de los dirigentes de los partidos gubernamentales y de oposición», Caracas, 4 de julio de 1962, AGA, 54/11877, PE, n. 448, f. 3.

22 Velásquez, 1979, 255-257.

23 Mondolfi Gudat, 2015, 42-43, 93, 237-238 y 411-412.

24 Telegrama cifrado urgente n. ${ }^{\circ} 115,9$ de noviembre de 1959, AGA, 54/11865. 
brindado a los adecos en las primeras dos elecciones. ${ }^{25}$ Además de esta creciente inestabilidad en las calles de Caracas, el gobierno de Betancourt se enfrentó a otros desafíos internos que lo hicieron tambalear. Los más importantes, antes de la cristalización de la estrategia guerrillera, fueron la ruptura de la coalición de gobierno, las diferentes escisiones producidas en AD y, sobre todo, las intentonas golpistas de 1961 y 1962. Las dificultades en el gobierno fueron seguidas con atención por parte de la embajada, quien enviaba al Ministerio recortes de periódicos que ilustraban la difícil situación existente en el seno del gobierno tripartito. ${ }^{26}$ Una situación que estaba abocada al fracaso desde el principio debido a la realidad interna de la Unión Republicana Democrática (URD) y a la difícil relación que esta agrupación tenía con los procesos que se estaban produciendo tanto dentro como fuera de las fronteras venezolanas.

Con respecto a los sucesivos golpes de Estado pasará una situación muy curiosa y es que mientras el «ruido de sables» y las informaciones de golpes de Estado inminentes serán constantes y serán informadas con bastante asiduidad, ${ }^{27}$ se hablará relativamente poco de las intentonas más importantes. Tanto el temprano y fallido golpe de Estado de Castro León, ${ }^{28}$ como los desiguales y posteriores golpes militares de Carúpano y Puerto Cabello, sin duda las expresiones más profundas de aquel deseo - extendido en ciertos sectores del ejército y de los partidos- de acabar con el nuevo régimen por la vía del levantamiento cívico-militar, produjeron escasa información vista la relevancia de los hechos. El Carupanazo, producido el día 4 de mayo, le costaría la vida al menos a cuarenta personas, ${ }^{29}$ mientras que el llamado Porteñazo, heredero directo de la intentona anterior y

25 En 1958, AD vence en casi todos los estados del país, siendo segunda fuerza en algunos en la zona central (Miranda, Aragua) y en algunos de la zona andina donde gana COPEI (Comité de Organización Política Electoral Independiente), leal socio de gobierno. La debacle se produce en el Distrito Federal, donde es última por detrás de las otras tres opciones. Esta situación se reproduce en 1963 ya que, a pesar del desgaste y de que las opciones electorales se doblan, siguen manteniendo su primacía en la mayor parte de los estados del país. Esta situación nos habla de una mayoría adeca en el país y de una zona de Caracas y alrededores más hostiles que, por cuestiones de centralismo informativo, dan una sensación errónea incluso a los propios revolucionarios.

26 «emite recorte de prensa con texto documento presentado por el partido URD al Presidente Betancourt», Caracas, 4 de noviembre de 1959, AGA, 54/11855, PE, n. 537.

27 Telegrama cifrado urgente n. ${ }^{\circ} 115$, Caracas, 9 de noviembre de 1959, AGA, 54/11865. «Levantamiento subversivo en Maiquetía», Caracas, 26 de diciembre de 1960, AGA, 54/11868, PE, n. 1467, f. 3. «Denuncia Secretario Gral. A.D. conspiración contra plan Betancourt», Caracas, 8 de mayo de 1961, AGA, 54/11876, PE, n. 652, f. 1.

28 Velásquez, 1979, 247-248.

29 Mondolfi Gudat, 2015, 316-322. 
producido apenas un mes más tarde, produjo un saldo mayor de muertos, superando los cuatrocientos. ${ }^{30}$ Las fallidas intentonas de mayo y junio de 1962 supusieron el apaciguamiento de los cuarteles venezolanos durante varias décadas, y un respiro para la república en ciernes, pero también produjeron un cambio en la vía principal para tomar el poder por parte de los grupos subversivos de izquierdas, de los levantamientos se pasó a unas guerrillas que llamaron mucho más la atención de la embajada española que estos golpes de Estado fallidos.

Que no existiera una gran profusión de información no quiere decir que no existieran menciones expresa. Por ejemplo, Saro y Posada, en un informe sobre la situación política en el país enviado al mes de producirse el fracaso de Puerto Cabello, definía los golpes como «violentos» y «extremistas». ${ }^{31}$ Resulta relevante la acusación de extremistas, puesto que, en un informe posterior, el mismo Saro y Posada hablaría de la participación en los golpes fallidos de Eloy Torres y Simón Sáez Mérida, a los cuales vaticinaba una pronta detención. ${ }^{32}$ Tanto Torres como Sáez Mérida eran diputados y pertenecían a partidos políticos de izquierda. En ese entonces, Sáez Mérida era miembro de la Cámara por el Movimiento de Izquierda Revolucionaria (MIR) y Torres lo era por el Partido Comunista de Venezuela (PCV), y la implicación de los dos en el Carupanazo era y es difícil de rebatir, ${ }^{33}$ aunque no aparezcan como firmantes del manifiesto lanzado por el sector levantisco de las fuerzas armadas que lo protagoniza. ${ }^{34} \mathrm{La}$ participación de estos actores de primer nivel muestra que, en ese entonces, al menos un sector importante de la izquierda revolucionaria ya había tomado la decisión de acabar con el gobierno por medio de cualquier vía. En cuanto a las bajas, para el Porteñazo la embajada habla de «cerca de mil muertos», ${ }^{35}$ una cifra que $a$ posteriori puede resultar exagerada a pesar de lo cruento de la batalla. En comparación con estos datos, la mayor parte de la prensa española e internacional manejaban unas cifras más cercanas a

30 Ibidem, 413-451.

31 «Reunión "en la cumbre” de...», 4 de julio de 1962, AGA, 54/11877, PE, n. 448, f. 1.

32 «Nueva reunión de la conferencia de "alto nivel" entre los representantes de los partidos políticos de Venezuela», Caracas, 26 de julio de 1962, AGA, 54/11877, PE, n. 500, f. 2.

33 Alexander, 1964, 111. Rodríguez, 2001, 128-129. Buttó, 2015, 530. Mondolfi Gudat, 2015, 336-340.

34 «anifiesto de las Fuerzas Armadas al pueblo y la nación», Carúpano, 4 de mayo de 1962, Centro de Documentación de los Movimientos Armados, Valencia (CEDEMA), Fondo Venezuela, Sección Movimiento 4 de Mayo.

35 «Reunión "en la cumbre” de...», 4 de julio de 1962, AGA, 54/11877, PE, n. 448, f. 1. 
las cuatrocientas bajas que dejó la intentona. ${ }^{36}$ Según la embajada, a pesar de que estos levantamientos agudizaron «la inestabilidad política y social que viene sufriendo el país», ${ }^{37}$ la dificultad de la coyuntura propició un acercamiento político entre los dos partidos en el poder y la oposición no revolucionaria. ${ }^{38}$

Si bien la imagen que se tenía de Betancourt había ido cambiando con el avance del tiempo, una situación algo diferente pasaría con su partido. Como se ha podido ver, $\mathrm{AD}$ era un partido con una implantación territorial y electoral fortísima, pero también con una heterogeneidad interna considerable, que fue saliendo a relucir con el tiempo. En principio era una agrupación hostil, no solo desde el punto de vista ideológico sino también por su tradicional y acentuado antifranquismo. AD no solo había roto relaciones con España durante el trienio que llevaba su nombre, sino que había dado soporte a agrupaciones antifranquistas, como la Junta de Amigos de los Republicanos Españoles, de la cual formaban parte activa. ${ }^{39}$ También habían acogido en su seno a gran parte del exilio anarquista y que había encontrado en sindicatos afines, una forma de canalizar sus aspiraciones de mejora social. ${ }^{40}$

En cuanto a la dinámica interna del partido, a medida que la legación española observaba que el gobierno no iba a resultar rupturista, fueron perdiendo interés por las cuestiones que estos ideológicamente defendían. Lo que sí les llamaba la atención a los cargos más altos de la embajada es la heterogeneidad interna y las divisiones que existían y que fueron progresivamente cristalizando. La primera, la del MIR, no fue para nada inesperada porque ya desde noviembre de 1959 la embajada informaba de la existencia de dos alas en el partido, una procomunista y otra anticomunista, ${ }^{41}$ las cuales se fueron distanciando cada vez más hasta la ruptura del año siguiente.

36 Por ejemplo, The New York Times hablaba primero de 150 muertos para años más tarde hablar de aproximadamente 200 víctimas. Mientras que La Vanguardia Española dio una primera estimación de 35, para un día más tarde hablar de 400 muertes. «Venezuela Says Revolts is Ended», The New York Times, Nueva York, 5 de junio de 1962, 3. «Ponte Rodríguez, 44, Foe of Betancourt», The New York Times, 26 de julio de 1964, 57. «La revolución venezolana de Puerto Cabello, yugulada», La Vanguardia Española, Barcelona, 5 de junio de 1962, 16. «Puerto Cabello: La fracasada sublevación ha causado más de cuatrocientos muertos», La Vanguardia Española, 6 de junio de 1962, 19.

37 «Reunión "en la cumbre" de...», 4 de julio de 1962, AGA, 54/11877, PE, n. 448, f. 1.

38 Ibidem, ff. 1-4.

39 Marquès Sureda y Martín Frechilla, 2002, 41-48. Martín Frechilla, 2006, 193, 199-201, 225, 232-233.

40 De Paz Sánchez y Luis León, 2019, 41-50.

41 Telegrama cifrado urgente $n .^{\circ}$ 115, Caracas, 9 de noviembre de 1959, AGA, 54/11865. 
La segunda escisión, producida a principios de 1962 pero anunciada algo antes, fue menos previsible pero también menos traumática, puesto que tenían un componente más personalista y menos revolucionario..$^{42} \mathrm{El}$ «Grupo ARS», que más tarde tomaría el nombre de «AD-Oposición», tomaría su propio camino a principios de 1962 y nunca regresaría al seno de AD. Desde luego que estas divisiones debilitaban la estructura de un gobierno que tendría más problemas legislativos que al principio del mandato. La embajada española consideraba al Grupo ARS un movimiento menos peligroso que el MIR, pero más cohesionado,${ }^{43}$ lo cual es lógico debido al peso que tenía su líder, el portugueseño Raúl Ramos Giménez. Dicho lo cual, resulta interesante trazar una línea entre las experiencias del llamado Grupo ARS y del MIR porque, a pesar de la relación esporádica que pudieron mantener entre ellos en cierto tiempo, resultan dos experiencias significativas y diferentes de los dos modelos de oposición que se construyeron frente al gobierno.

\section{La incipiente dinámica política: los otros partidos}

Toda democracia liberal representativa necesita de una pluralidad que construya su proposición teórica en un hecho efectivo y este papel lo juegan los partidos. Maurice Duverger ya describió que para que la democracia sea identificable como sistema político debe haber pluralidad de partidos y que es el reconocimiento explícito de los que se encuentran en la oposición, lo que le otorga una definición plausible. ${ }^{44} \mathrm{Si}$ tomamos una foto fija de principios de 1962, podemos encontrar en Venezuela seis estructuras partidarias bien definidas. Estos seis partidos se pueden agrupar en parejas sin mayor dificultad. En primer lugar, tenemos a los dos partidos que formaban parte del gobierno, AD y COPEI, y luego los partidos de oposición que, a su vez, se pueden subdividir en dos grupos. Siguiendo la teorización que realiza Juan José Linz, ${ }^{45}$ por un lado estaba la llamada oposición leal, conformada por el Grupo ARS y la vertiente institucional del URD (Grupo ARS) y, por otro, la oposición desleal, conformada por el MIR y el PCV. Desde luego que la realidad política era más compleja que esas tres subestructuras,

42 Martz, 1966, 183-191.

43 «Reunión "en la cumbre" de...», 4 de julio de 1962, AGA, 54/11877, PE, n. 448, f. 2.

44 Duverger, 1969.

45 Linz y Stepan, 1978. Ampliado y más específico en Linz, 1987, 57-72. 
existían otras corrientes que cristalizarán a medida que pase ese año y el siguiente y se acabarán coordinando, pero como estructuras estables y bien definidas, en 1962, solo existían esas.

Los partidos de la llamada «oposición desleal» son aquellos que más atención generaron en la legación caraqueña. A pesar de la inestabilidad que generaban, la diplomacia española sobreestimó a menudo el peso de los comunistas en ciertos sectores del país. Más allá del ya mencionado y constante ruido de sables relacionado con el comunismo, se hacía mención a la implicación de comunistas en todos los sectores sociales. En un telegrama de noviembre de 1959 se mencionaba su infiltración entre los telegrafistas, ejército, «prensa, radio, televisión, así como Magisterio y Universidad». ${ }^{4}$ Había una cierta psicosis con el comunismo venezolano, lo que lleva al embajador a informar al ministerio de que Guillermo Machado visitaría España. Guillermo era hermano del jefe del PCV y lo que se quería evitar es una confusión que le generara un problema a este personaje que era conocido del marqués de Saavedra ${ }^{47}$ En ese trasvase de información hablan de un recuento de afiliados al PCV dado por la revista norteamericana Visión. En la misma se dice que en Venezuela hay 26.000 afiliados comunistas para inicios de 1959, añadiendo que la organización era «todavía débil», pero que «iba creciendo rápidamente tanto desde el punto de vista numérico como de influencia política». ${ }^{48}$ Estos datos son certeros ya que durante los primeros años de la democracia en Venezuela hubo un incremento de la afiliación al PCV, el cual llegó a su pico, según Alexander, en el año 1961, cuando alcanzaron los 40.000 .49

Una de las cuestiones más interesantes que se plantean desde la embajada es que, desde un primer momento, se diferencia entre el PCV y el MIR, al menos el marqués de Saavedra lo hace. Ante las palabras de uno de los líderes de la agrupación desgajada de AD, Américo Martín, de que la unión entre ambos partidos se produciría «una vez que resuelvan sus actuales diferencias», Saavedra mostró sus serios reparos. ${ }^{50}$ Para el embajador las diferencias principales eran dos. Por un lado, consideraba que

46 Telegrama cifrado urgente n. ${ }^{\circ} 115$, Caracas, 9 de noviembre de 1959, AGA, 54/11865.

47 «Viaja a España D. Guillermo Machado, hermano Jefe Partido comunista Venezuela», Caracas, 25 de abril de 1960, AGA, 54/11874, PE, n. 213.

48 «Peligro rojo en el continente americano», Caracas, 7 de enero de 1959, AGA, 54/11867, PE, n. 9, f. 1.

49 Alexander, 1971, 137-138.

50 «Noticia aparecida esta prensa sobre posible unión partidos Comunista y M.I.R.», Caracas, 17 de mayo de 1961, AGA, 54/11875, PE, n. 715. 
«a los directores del comunismo venezolano y a sus jefes del comunismo mundial, no parece que pueda interesarles tal fusión, ya que el M.I.R., [...] atrae cierta masa de universitarios e intelectuales reticentes a ingresar en el partido Comunista». ${ }^{51}$ Por otro lado, hablaba de diferencias individuales las cuales consideraba que en Venezuela, eran «a veces más difíciles de resolver que las relativas a cuestiones doctrinales» ${ }^{52}$ Es cierto que ambos partidos colaboraron en muchos momentos de su historia: participaron de la mano en las protestas, en los intentos fallidos de golpe de Estado o en la implementación de la estrategia guerrillera. ${ }^{53}$ Sin ir más lejos, ambos partidos fueron ilegalizados en el mismo día y bajo el mismo decreto, ${ }^{54}$ pero eran realidades complejas (sobre todo el PCV) y diferenciadas en algunos aspectos, y esto supo verlo la embajada en un momento en el que no era extraño pensar en una integración.

A pesar de esa diferencia dentro de la cercanía, la embajada siempre identificó al MIR como un partido de «extrema izquierda», ${ }^{55}$ revolucionario y con un alto grado de antiamericanismo. ${ }^{56}$ Sin duda alguna, el MIR siempre fue un partido mucho más efervescente, resultando clave su influencia a la hora de entender el viraje violento emprendido por el PCV. ${ }^{57}$ En lo que afectaba a España, también influía esta realidad, ya que gran parte de los líderes del MIR asumieron posturas antifranquistas más cercanas al posicionamiento adeco de los cuarenta que de los sesenta.

En cuanto a lo que se clasifica como oposición leal se distinguían dos grupos diferenciados. Por un lado, aquel grupo escindido de AD y del que ya se ha hablado en el epígrafe anterior y, por otro, un partido esencial para entender la dinámica política de mediados de centuria en Venezuela: la URD. Por su importancia institucional, y a la vez por el peso que tendrán sus actuaciones dentro de la dinámica política, la URD será el partido que más atención recibirá por parte de la embajada. No se pueden obviar dos aspectos que se suelen pasar por alto cuando se habla de la dinámica partidista en

51 Idem.

52 Idem.

53 Para conocer la participación en la lucha guerrillera se recomienda: Mondolfi Gudat, 2018.

54 Decreto $\mathrm{N}^{\mathrm{o}}$ 752, Caracas, 9 de mayo de 1962, CEDEMA, Valencia, Venezuela, Otros Documentos.

55 «isturbios en la Universidad Central de Venezuela», Caracas, 19 de diciembre de 1960, AGA, 54/11868, PE, n. 1408, f. 1.; «Situación de la Universidad en Venezuela, en relación con los últimos disturbios», Caracas, 12 de diciembre de 1960, AGA, 54/11870-009, PE, n. 1367, f. 6.

56 «ATAQUE COMUNISTA A MOSCOSO. Diario El Mundo», Caracas, 30 de junio de 1961, AGA, 54/11875, PE, Oficina de Información Diplomática, n. 889.

57 Alexander, 1971. Robledo Limón, 1971, 533-534. Mondolfi Gudat, 2015, 58-65. 
Venezuela. La primera es la simplificación del sistema de partidos como un bipartidismo adeco-copeyano durante todo el período. La realidad no solo no concuerda con esto,$^{58}$ sino que obvia que la URD fue el segundo partido en 1958 y que firmó Puntofijo, entrando a formar parte del gobierno.

Pero a los pocos meses de formarse el gobierno, ya la URD parecía un partido de difícil gestión. Unas dificultades que ya eran percibidas por la embajada española de manera temprana, ya que se caracterizaba a la URD como un «partido procomunista por táctica política contra Acción Democrática». ${ }^{59}$ Ese enfrentamiento con la política de $\mathrm{AD}$, acabaría por hacerles salir del gobierno y que sus ministros presentaran la dimisión a finales de 1960. Esta situación era vista por parte de la embajada como una «total falta de inteligencia» por parte de ambos partidos que ahondaban sus diferencias a medida que el tiempo pasaba. ${ }^{60}$

En cierta medida, el antibetancourismo funcionaba en los primeros momentos como un pegamento entre las diferentes facciones de la URD. Jóvito Villalba era el líder del partido, pero la división interna era fácilmente palpable como lo visualizó la embajada. Hombres como Miquilena o López Orihuela mantenían un posicionamiento político más agresivo que el de Villalba e intentaban significarse en ese sentido. ${ }^{61}$ En un movimiento que en parte se justificaba en el convencimiento, pero en otra se basaba en el intento de aplacar a los sectores más radicales, Villalba fue aproximando el partido hacia el posicionamiento de los sectores de oposición más radical y comenzó a mantener contactos con los liderazgos del PCV y el MIR, en un movimiento que la embajada española tildó de «penosa sorpresa». ${ }^{62} \mathrm{La}$ colaboración con el PCV no era una novedad, ya lo habían hecho antes apoyando la candidatura de un Larrazábal que había funcionado como aglutinador de sectores progresistas contrarios a AD.

Larrazábal jugaría siempre un papel autónomo e independiente de sus antiguos apoyos partidistas. La embajada enviaba a Madrid un recorte del diario La Esfera en el que se publicaba el rechazo de Larrazábal a los planes de Villalba de encabezar un frente de oposición liderado por el militar y del que formarían parte junto al MIR, el al PCV y a otros sectores contrarios al

58 Encajaría en lo que Sartori $(2005,224-239)$ definió como un sistema de pluralismo moderado.

59 Telegrama cifrado urgente n. ${ }^{\circ} 115$, Caracas, 9 de noviembre de 1959, AGA, 54/11865.

60 «Situación política de Venezuela», Caracas, 8 de noviembre de 1960, AGA, 54/11868, PE, n. 1149 , f. 1.

61 Ibidem, ff. 1-2.

62 Ibidem, f. 1. 
gobierno. ${ }^{63}$ Según este recorte del diario perteneciente a la Cadena Capriles, que sin duda alguna se congratulaba con la información, ${ }^{64}$ Larrazábal no solo había rechazado la proposición y reiterado su adhesión explícita al gobierno liderado por Betancourt, lo que suponía un duro golpe a la conformación del frente, sino que además había mostrado su disconformidad con el hecho de que la URD le considerara un hombre sujeto al partido. ${ }^{65}$ El caso del almirante había sido bastante llamativo, presidente provisional durante el año 1958, había llamado a elecciones de manera rápida ese mismo año y había cedido el cargo para poder presentarse. Una vez pierde los comicios contra Betancourt decide, por iniciativa del presidente, jugar un papel institucional y salir como embajador a Santiago de Chile, desde donde mostrará nuevamente y en diversas ocasiones, sus férreas convicciones democráticas. ${ }^{66}$ Esta decisión, que a posteriori resultaría un suicidio político, le otorga aún más valor a sus decisiones, ya que como afirmaba la embajada en Caracas, su prestigio entre las clases populares (sobre todo de la región central y metropolitana), aunque estaba disminuyendo, aún existía. ${ }^{67}$

Este acercamiento de la URD a las fuerzas de oposición será progresivo a medida que avance 1961. Por este movimiento, el partido será tildada de «separatista y disidente» por parte de la embajada. ${ }^{68}$ Además, tras la negativa de Larrazábal a liderar a todos los sectores antibetancourianos, se irán haciendo cada vez más evidentes las divisiones en su seno, unas divisiones que serán percibidas en numerosas ocasiones. ${ }^{69} \mathrm{La}$ realidad es que más que Betancourt, quien puso a la URD frente al espejo fue su acercamiento a la izquierda revolucionaria. Entre los múltiples sectores existentes en el partido destacaban dos líneas principales de estrategia política, por un lado los que buscaban seguir la estrategia opositora de Villalba, más leal y moderada; y por otro, los proclives a una mayor y más estrecha colaboración con el PCV y el MIR, dos partidos que no dudaban en atentar contra la

63 «Posición política del Vicealmirante Larrazábal», Caracas, 2 de diciembre de 1960, AGA, 54/11870, PE, n. 1290. Recorte diario La Esfera del 1 de diciembre de 1961.

64 La Esfera fue un diario caraqueño adquirido por Miguel Ángel Capriles y que, al menos durante la primera presidencia, se mostró bastante cercano a las posiciones del gobierno. Véase Capriles, 1973.

65 «Posición política...», 2 de diciembre de 1960, AGA, 54/11870, PE, n. 1290.

66 Luis León y De Paz Sánchez, 2018.

67 «Posición política...», 2 de diciembre de 1960, AGA, 54/11870, PE, n. 1290, f. 1.

68 «elaciones entre U.R.D. y A.D.», Caracas, 13 de abril de 1959, AGA, 54/11867, PE, n. 142 .

69 Como muestra, pueden verse Idem o «Reunión "en la cumbre"...», Caracas, 4 de julio de 1962, AGA, 54/11877, PE, n. 448. 
legalidad republicana. ${ }^{70}$ A finales de 1961, cuando la división era evidente, Villalba tuvo que salir a afirmar que la «URD no es ni puede ser un partido marxista», en un movimiento que el embajador español percibe como electoralista de cara a las elecciones de $1963 .{ }^{71}$ Es cierto que la URD no era un partido marxista y que este mensaje iba más hacia el otro sector del partido que hacia un electorado al que aún le quedaban años para volver a presentarse ante las urnas. Pero no es menos cierto que el hecho de que no fuera un partido genuinamente comunista, no implica que no tuviera en su seno personalidades afines al pensamiento marxista. Desde luego, el partido reclamaba una tradición liberal y tampoco es que la agrupación (al menos en su totalidad) pueda considerarse plenamente insertada en esa corriente.

Además de la figura de Villalba, era el sector izquierdista el que más atracción generaba a la embajada española. Las informaciones sobre el posicionamiento de figuras como Fabricio Ojeda o Luis Miquilena serían asiduas. Entre las informaciones que se enviaban a Madrid destaca un recorte del diario La Esfera, en el que se publica la participación de sectores de la URD, y entre ellos del propio Miquilena, en un sabotaje antirrepublicano. ${ }^{72}$ Los intentos de toma del poder por vías armadas serían lo que acabarían por dividir la URD. Muchos de los integrantes de la línea dura acabarían formando parte de frentes guerrilleros. ${ }^{73}$ Entre ellos destacaría Ojeda, quien se acabaría convirtiendo en el hombre de Castro en Venezuela, y que no dudaría en anunciar su subida a las montañas para «continuar la lucha revolucionaria por la liberación de Venezuela» en una carta de renuncia al legislativo venezolano ${ }^{74}$ del cual aun formaba parte.

En esta situación partidista de profundo y progresivo enconamiento que la embajada española llegó a definir como de «guerra civil fría», ${ }^{75}$

70 En realidad, se puede hablar de un tercer sector, mucho más centrado e incluso de centroderecha, en el que destacaban personalidades cercanas al partido como Arturo Uslar-Pietri, quien fue elegido diputado por la URD en las elecciones de 1958 y que más tarde la abandonaría formando un proyecto propio.

71 «Remito recorte El Mundo, día ocho, con declaraciones del Dr. Jóvito Villalba, Jefe de U.R.D.», Caracas, 12 de noviembre de 1961, AGA, 54/11870, PE, n. 1234, ff. 1-2.

72 «Remite recorte La Esfera, de 30 del actual, dando la noticia de haberse descubierto plan extremista de sabotaje y guerrillas», Caracas, 31 de marzo de 1962, AGA, 54/11871, PE, Oficina de Información Diplomática, n. 184.

73 Irwin y Micett, 2008, 221-222.

74 «Carta de renuncia de Fabricio Ojeda», Caracas, 30 de junio de 1962, CEDEMA, Fondo Venezuela, Sección Frente de Liberación Nacional-Fuerzas Armadas de Liberación Nacional (FALN).

75 «Situación política de Venezuela», 8 de noviembre de 1960, AGA, 54/11868, PE, n. 1149 , f. 3 . 
gran parte de sus esperanzas estaban puestas en el gobierno y, sobre todo, en el leal socio del presidente: COPEI. A pesar de que COPEI nunca fue un partido cercano al franquismo, ni mucho menos apoyaba expresiones autoritarias de derecha ${ }^{76}$ su posición en el poder funcionaba como una especie de freno ante un hipotético viraje de Betancourt. La realidad es que la confianza que tenía la embajada en el grupo de Caldera era considerable. El embajador Valdés lo observaba un como árbitro en la enconada división que se estaba produciendo entre AD y la URD. ${ }^{77}$ Está claro que, durante esta convulsa etapa de conformación democrática y partidista, sería la agrupación política que menos convulsiones internas soportaría (aunque no estuvo exento), en parte debido a la primacía indiscutible de su líder. Esta tranquilidad también les permitió desarrollar una agenda política más estable durante todo el mandato. Según la embajada, COPEI condicionaba la política gubernamental. Supuestamente, el presidente Betancourt no veía con malos ojos la implementación de alguna relación de colaboración con la URSS durante los primeros años de su gobierno. ${ }^{78}$ Incluso se llega a hablar de algún tímido acercamiento del presidente con contactos soviéticos como es el caso del embajador en México. La embajada resalta siempre la lealtad existente entre COPEI y AD durante todo el período de estudio, aunque también hace llegar a Madrid unas declaraciones de Caldera en las que afirma que si se establecen relaciones con la URSS, él mismo hará saltar la coalición por los aires ${ }^{79}$ Esta aseveración resulta muy curiosa puesto que sería el propio Rafael Caldera desde la presidencia, quien precisamente acabaría normalizando las relaciones con la propia Unión Soviética. ${ }^{80}$ En resumidas cuentas, desde la embajada mostraban una buena predisposición hacia el gobierno puesto que observaban a COPEI como una garantía ante ciertas cuestiones.

No es extraño que se produjera este pensamiento acerca de COPEI, si observamos que no deja de ser la opción más a la derecha de las cuatro

76 COPEI era un partido socialcristiano con vocación democrática. El elemento aglutinador de su variopinta conformación eran los valores cristianos, pero dentro de la agrupación se pueden observar conviviendo, sin mayores dificultades, militantes y cuadros de centro derecha con otros sectores reformistas. Véase Coppedge, 2000, 111-115.

77 «Relaciones entre U.R.D. y A.D.», 13 de abril de 1959, AGA, 54/11867, PE, n. 142.

78 «Relaciones diplomática de Venezuela con la URSS», Caracas, 17 de octubre de 1960, AGA, 54/11868, PE, n. 1003.

79 «Situación crisis política venezolana», Caracas, 27 de septiembre de 1960, AGA, 54/11868, PE, n. 894.

80 Romero, 1992, 76-78. 
que se presentan a las elecciones, pero en Venezuela seguía existiendo una corriente política derechista y autoritaria que, aunque no se había organizado políticamente, seguía teniendo un peso moral e histórico: el perezjimenismo. Pérez Jiménez había abandonado el país en enero de 1958 pero seguiría jugando un papel considerable durante varias décadas. Su sombra era alargada y seguiría generando más de un quebradero de cabeza a los políticos republicanos que le sucedieron. ${ }^{81}$ Durante el cambio de década, el ex dictador se encontraba en Miami intentando eludir la propuesta de extradición que Betancourt cursaba contra él, ${ }^{82}$ pero el perezjimenismo seguía existiendo en Venezuela. Por ello, llama la atención la escasa información que se trasvasa a Madrid acerca de lo que se podría denominar como el «perezjimenismo político», que sin duda alguna existía, aunque no se institucionalizaría hasta pocos años más tarde.

Lo más parecido al perezjimenismo fue un partido bastante escorado a la derecha llamado Movimiento Acción Nacional (MAN). Este nacería en mayo de 1960 y sería legalizado en agosto, y aunque sería creado por una cúpula más o menos cerrada de hombres católicos y fuertemente antizquierdistas, ${ }^{83}$ su liderazgo indiscutible pasaba por la figura de Germán Borregales. Aunque Borregales siempre fue un férreo crítico del gobierno, las declaraciones que más llamaron la atención de la embajada siempre se debieron a problemas de asuntos exteriores, como por ejemplo su aseveración de que tenía «quinientos voluntarios listos para viajar a Cuba en cualquier momento [para combatir]». ${ }^{84}$ En cierta medida, se presentía la escasa relevancia del MAN, ${ }^{85}$ ya que en la mayoría de informaciones que hablaban sobre las diferentes tendencias políticas existentes en el país, se les obviaba.

En definitiva, la embajada percibía la importancia de cada partido, de cada corriente política, así como también percibió que los movimientos producidos en Carúpano y Puerto Cabello, y sus más inmediatas consecuencias en forma de apoyo o repudio. Estas intentonas fueron las que definieron en

81 Velásquez, 1979, 278-279, 313, 346-347 y 388-390.

82 Ewell, 1977.

83 Magallanes, 1973, 473.

84 «Extremistas voluntarios para Cuba», Caracas, 20 de abril de 1961, AGA, 54/11876, PE, n. 558 , ff. $1-2$.

85 El MAN se presentó a varias elecciones y su mayor logro sería conseguir un diputado en las elecciones de 1968. Por hacer una comparación con la marca original perezjimenista, la Cruzada Cívica Nacionalista $(\mathrm{CCN})$, este grupo sí que consiguió éxitos relativos como ser la cuarta fuerza más votada en las elecciones de 1968 (21 diputados y 4 senadores), ganando las legislativas en el Distrito Federal. $C N E, 4$. 
qué coordenadas se encontraban los diferentes grupos que conformaban la heterogénea oposición al gobierno de Rómulo Betancourt. ${ }^{86}$ Tras esos movimientos y tras la toma de decisión autónoma de algunos sectores de la URD, la supuesta identidad de pareceres que, según Villalba, mantenían el PCV y la URD,${ }^{87}$ desparecieron, y con ellas, la posibilidad de generar un frente de oposición unido. Los siguientes años hasta los nuevos comicios supusieron acciones y reacciones, creaciones y divisiones entre las diferentes corrientes, que llevaron a que, en las nuevas elecciones de 1963, se multiplicaran las opciones presidenciales.

\section{La visión de los grupos sociales y económicos}

La dinámica política venezolana no solamente estaba definida por la actuación de los partidos políticos. Estos tenían un papel preponderante pero tampoco se puede obviar el rol que jugaban otras instituciones en la vida diaria del país y que fortalecían o minaban la estabilidad del experimento democrático en ciernes. La iglesia, los actores sociales, los estudiantes o la propia prensa, a la que se le dedicará un epígrafe aparte, recibían la mirada constante de una embajada española en Caracas que conocía el papel que estos y otros actores estaban jugando.

Como era lógico, a la embajada española le importaba especialmente la relación de la iglesia con la nueva república. Al igual que se ha podido observar con respecto a COPEI, la situación de todo lo que rodeara al catolicismo venezolano llamaba especialmente la atención. En realidad, la respuesta general de la iglesia con respecto al nuevo régimen y al gobierno puntofijista fue positiva, ${ }^{88} \mathrm{y}$ esto fue recogido ampliamente por la embajada. En un documento de septiembre de 1960, se recogían unas declaraciones de monseñor Quintero, arzobispo de Caracas, en las que se afirmaba que «la coalición es ventajosa para el afianzamiento del régimen de derecho y para ahorrar pugnas inútiles» ${ }^{89}$ Además de ello, Quintero halagaba a la figura y el discurso de Rómulo Betancourt, definiéndolo como «sereno, mesurado

86 «Nueva reunión de...», 26 de julio de 1962, AGA, 54/11877, PE, n. 500, f. 2. «Reunión "en la cumbre" de...», 4 de julio de 1962, AGA, 54/11877, PE, n. 448.

87 «Situación política de Venezuela», 8 de noviembre de 1960, AGA, 54/11868, PE, n. 1149 , f. 3 .

88 Rodríguez Campos, 2009, 583-584.

89 «Situación política de Venezuela», 8 de noviembre de 1960, AGA, 54/11868, PE, n. 1149 , f. 3 . 
y optimista». ${ }^{90}$ Esta fue la tónica general de las relaciones iglesia-gobierno durante los primeros años, aunque también hubo casos aislados de curas cercanos al comunismo, en algunos casos bastante críticos con el franquismo y que recibían cierta atención mediática, como es el caso del padre Juan de Dios Andrade, sacerdote de Valera ${ }^{91}$ Atención que era recogida y públicamente criticada por la embajada española en Caracas. Dicho lo anterior, la profusión de curas comunistas por Venezuela no fue muy amplia, por lo menos no comparado con otras regiones del continente, y la situación estuvo controlada por la jerarquía eclesiástica. Una jerarquía que buscó con insistencia un encuadre legal de la relación Iglesia-Estado, ${ }^{92}$ encuadre que acabaría recibiendo de parte de los gobiernos adecos en forma de modus vivendi, firmado en $1964 . .^{93}$

En cuanto a los actores sociales, estos también recibieron la atención de la embajada española, pero mientras la información referente a los sindicatos fue prolífica y cambiante, la de la patronal no lo fue tanto. La realidad es que la imagen que se daba de Fedecámaras, la principal agrupación empresarial del país, es que esta apoyaba al gobierno. ${ }^{94}$ Sin embargo, la situación con los sindicatos era mucho más compleja. El predominio en los sectores sindicales siempre fue más difícil de situar por parte de la embajada. En buena parte es lógico ya que los sindicatos tenían una mayor complejidad cuantitativa y cualitativa que la patronal, lo que dificultaba el rastreo. Lo cierto es que, en la primavera de 1959, un informe de Manuel Valdés afirmaba que el PCV «en la actualidad controla casi totalmente los sindicatos», ${ }^{95}$ pero esta afirmación no encajaba del todo con la realidad. La mayor parte de los sindicatos se encontraban dominados por los adecos, que eran mayoritarios en casi todas las ramas, ${ }^{96}$ hecho que también constataría la propia embajada en un documento de finales de $1960 .{ }^{97}$

90 Idem.

91 «emite recorte prensa El Nacional con declaraciones del Padre Juan de Dios Andrade, ofensivas para España», Caracas, 24 de julio de 1961, AGA, 54/11875, PE, Oficina de Información Diplomática, n. 951.

92 «ituación política de Venezuela», 8 de noviembre de 1960, AGA, 54/11868, PE, n. 1149, ff. 3-4.

93 Rodríguez Campos, 2009, 584

94 «Tensión relaciones Cuba-Venezuela», Caracas, 8 de noviembre de 1960, AGA, 54/11868, PE, n. 1147, ff. 1-2.

95 «elaciones entre U.R.D. y A.D.», 13 de abril de 1959, AGA, 54/11867, PE, n. 142, f. 1.

96 Urquijo García, 2004, 26-32.

97 «Tensión relaciones Cuba-Venezuela», 8 de noviembre de 1960, AGA, 54/11868, PE, n. 1147 , f. 2 . 
Esta primera información errónea pudo deberse a un cúmulo de factores. El primero de estos factores tiene que ver con es el marcado sesgo anticomunista del emisor, el embajador Valdés, el cual era mucho más marcado que el de sus sucesores, pero también influyen cuestiones contextuales. Por un lado, nos encontramos con las dificultades para medir el peso real que tenía cada agrupación en el seno sindical previo al desarrollo de gran parte de las elecciones internas, es decir, ya dentro del sistema democrático. También influye la creciente inestabilidad social pero también sindical que se fue generalizando en Venezuela. Una situación que se amplió al hacer su aparición los grupos sindicales afines al MIR, que junto a los comunistas se mostraron bastante activos y beligerantes ${ }^{98}$, aunque hay que reconocer que esto influye en mucha menor medida, debido a lo temprano de la información anteriormente mencionada. Además de todo ello, no se puede obviar tampoco el peso de la ya mencionada caraquización.

Un ambiente que se convertiría en bastante hostil para el gobierno sería el entorno educativo, que se mostraría realmente activo en las calles. La universidad venezolana, sobre todo la principal, la Universidad Central de Venezuela (UCV), se había convertido en un lugar complicado, y así lo hacía ver la diplomacia española. Dos fueron los momentos en los que más se intensificó el papel de la universidad dentro de la oposición al gobierno, al menos durante el período de estudio: el Popularazo $0^{99}$ y el incidente vivido por el presidente dentro del recinto de la UCV. Ambos se produjeron en un lapso de unos meses entre los años 1960 y 1961, pero para este estudio existe una notable diferencia. Mientras que el incidente del recinto tuvo bastante repercusión en la diplomacia hispana, la cuestión del Popularazo no recibió tanta atención específica y fue tomada como una continuidad de la realidad general que ya se estaba viviendo.

Durante el famoso incidente en la UCV, Betancourt fue rechazado por gran parte de su alumnado, recibiendo abucheos e incluso haciéndose muy famosa una pancarta que decía «Patíbulo para Betancourt». Esta situación encolerizó a varios sectores de la sociedad civil y de la política venezolana. También a la embajada española que rápidamente vertió críticas sobre el diario El Nacional y sobre el consejo universitario, ${ }^{100}$ responsabilizando a

98 «Suspensión dirigentes comunistas en Confederación Nacional del Trabajo», Caracas, 7 de junio de 1961, AGA, 54/11875, PE, n. 777.

99 Velásquez, 1979, 255-258.

100 «Insultos estudiantiles al Presidente de la República», Caracas, 31 de mayo de 1961, AGA, 54/11875, PE, n. 752. 
ambos de la delicada situación universitaria. Uno de los blancos principales de la embajada española sería el rector De Venanzi, a quien se responsabilizaba directamente de no poner coto a la situación de inestabilidad que se daba en su institución. En algunas informaciones se le definía como «de reconocida tendencia pro-comunista» y se le reprochaba, por ejemplo, el envío de más de setenta atletas a participar en los Juegos Universitarios Latinoamericanos, que se celebrarían en Cuba. ${ }^{101}$ En ocasiones se apuntaba no solo al mundo universitario sino también al político, ya que algunos encargados de negocios, consideraban que el problema de la universidad estaba en la excesiva libertad que había sido otorgada por el expresidente Edgar Sanabria durante su corta presidencia. ${ }^{102}$

A pesar de estas críticas, no se pueden obviar dos cuestiones. La primera es que la universidad venezolana se estaba abriendo a un público más amplio y heterogéneo, lo que mostraba un triunfo político y social del país. Durante los años de nuestro estudio y el siguiente (1958-1963), la cifra de estudiantes matriculados en las universidades públicas se multiplicó por cuatro. ${ }^{103}$ La segunda cuestión es que la realidad era mucho más heterogénea de lo que el trasvase de información propiciaba. La situación en otras universidades era diferente. Por ejemplo, los estudiantes de la UCAB mostraban también su posicionamiento político en las calles, generalmente anticomunista y propartidos gubernamentales, ${ }^{104}$ pero estos estudiantes eran mucho menos en número. ${ }^{105}$ Esta situación no solo se dio en el ámbito de la universidad privada, otros estudiantes de universidades públicas del país también mostraron su apoyo al gobierno. Dicho lo cual, el peso simbólico y pragmático de la UCV era fuerte. En 1962, la UCV representaba más del $50 \%$ del alumnado universitario que en Venezuela estudiaba en instituciones superiores de carácter público. ${ }^{106}$ Además de su peso en estudiantado,

101 «Comentarios desfavorables esta prensa contra Rector De Venanzi por atender invitación de Cuba», Caracas, 24 de septiembre de 1962, AGA, 54/11877, PE, n. 661.

102 «Triunfo de la plancha presentada por A.D. y COPEI sobre la de los comunistas, en las elecciones para Decanos de la Universidad Central de Venezuela», Caracas, 4 de julio de 1962, AGA, 54/11877, PE, n. 446.

103 Bífano, 2008, 145-146

104 «Manifestación anticomunista estudiantil», Caracas, 6 de mayo de 1961, AGA, 54/11876, PE, n. 650 .

105 La UCAB (Universidad Católica Andrés Bello) rondaba el millar y medio de estudiantes. Pírez Pérez, 2014. Esta cifra suponía alrededor de una décima parte de los estudiantes matriculados en la UCV.

106 Bífano, 2008, 145-146. 
su ubicación en la capital del país jugaba un papel destacado en la política nacional.

La UCV tampoco era un bloque monolítico. Según la diplomacia española había diferentes sentires en la universidad, pero los comunistas, que se hacían fuertes en algunos sectores de la institución intentaban canalizar la protesta de tipo estudiantil hacia la subversión política. ${ }^{107}$ Para ello, no solo azuzaban a los propios estudiantes que estaban matriculados en la UCV, sino que contaban también con el soporte de multitud de liceístas que eran trasladados a la Ciudad Universitaria cuando lo creían necesario. La situación era diferente según carreras y facultades. Por ejemplo, un documento de Pérez-Hernández identificaba a casi un $60 \%$ del profesorado de la Escuela Técnica Industrial como comunistas o miristas, argumentando que la industria del país «no puede estar en manos comunistas y acabará estándolo» si el profesorado sigue teniendo esas ideas políticas las cuales consideraba «contrarias a los principios básicos de la Nación como son respeto a las instituciones, religión y familia, idea de patria, etc.». ${ }^{108}$

La realidad es que la situación en la UCV era bastante activa en cuanto a efervescencia política, sobre todo durante los primeros años del gobierno. A medida que el enfrentamiento entre el gobierno y los grupos de izquierdas se radicalizó, estos perdieron su primacía en la institución. Según la embajada española, será la pérdida de apoyos entre el profesorado, y más concretamente la derrota en las elecciones a decanos de los candidatos afines al comunismo, lo que propició la dimisión de De Venanzi. ${ }^{109} \mathrm{El}$ rector saliente y sus grupos afines habían sido objeto de duras críticas por parte de la embajada española. No es de sorprender que la quema de banderas españolas en el recinto de la UCV, como protesta ante la situación política, molestara a la embajada (se molestan con las autoridades), puesto que lo observaban como un ataque directo. Otras críticas a la rectoría que la embajada haría llegar fueron las de la jerarquía eclesiástica venezolana, ${ }^{110}$ las cuales serían recibidas como una confirmación de sus sospechas.

La situación de inestabilidad de principios de los sesenta en parte era cierta y en parte se encontraba amplificada por la caraquización ya

107 «Huelga en la Universidad Central», Caracas, 6 de noviembre de 1961, AGA, 54/11870, PE, n. 1213.

108 «Disturbios en la Universidad Central de Venezuela», 19 de diciembre de 1960, AGA, 54/11868, PE, n. 1408.

109 «Triunfo de la plancha...», 4 de julio de 1962, AGA, 54/11877, PE, n. 446, f. 1.

110 «Situación de la Universidad...», 12 de diciembre de 1960, AGA, 54/11870-009, PE, n. 1367 , f. 4 . 
mencionada. Resulta llamativo que, en numerosas ocasiones, no se reconocieran las actividades subversivas de corte político como tal, sino que se les englobara dentro del concepto hampa. ${ }^{111}$ En realidad, esto suponía una forma de denostarlas rebajándolas al nivel de delincuentes comunes. Para la embajada, la inestabilidad propiciada no tenía diferencias. A finales de 1962, el encargado de negocios español en Caracas hablaba de «una situación de caos en la que cada ciudadano tiene que prever por su defensa, cada facción luchar contra su enemigo e incluso los cuerpos policiales adaptan los sistemas hamponiles». ${ }^{12}$

\section{España, gobierno y libertad de prensa}

Además de la escasa querencia que el personal de la embajada española (al menos una parte importante) tenía por la libertad de expresión y la libertad de cátedra, la libertad periodística no sería otro caballo de batalla a defender por parte de la embajada ibérica. En los documentos que se envían a Madrid, el personal se convertirá en eco activo de la situación mediática en el país, sin duda alguna un contexto rico y variado, pero donde también se sucedieron actuaciones que erosionaron la libertad de prensa. El marqués de Saavedra se hizo eco de una publicación del diario La Esfera, que en mayo de 1961 publicaba una información en la que hacía alusión a que la actitud gubernamental de apertura y reconocimiento de las libertades, más en concreto la libertad de prensa, era aprovechada por sectores cercanos a la URSS para crear un clima de opinión pública cercana a opciones de izquierda radical. ${ }^{113}$ Este mensaje servía para confirmar un sesgo que traía la legación de casa y es que la libertad de prensa era un elemento distorsionador del buen funcionamiento de una sociedad. Además de ello, no es cierto que la actitud del gobierno de Betancourt fuera laxa con la prensa. La bibliografía existente ya ha retratado una relación tirante entre el gobierno venezolano y los grupos de comunicación, un gobierno que en algunas

111 «Se agrava el problema de las actividades del hampa en Venezuela», Caracas, $18 \mathrm{de}$ septiembre de 1962, AGA, 54/11877, PE, n. 639.

112 «Creación de un nuevo cuerpo policial para combatir los desmanes del hampa en Venezuela», Caracas, 25 de setiembre de 1962, AGA, 54/11877, PE, n. 656, f. 2.

113 «"APROVECHAR LA OBJETIVIDAD DE LA PRENSA VENEZOLANA PARA CREAR ESTADO DE OPINIÓN FAVORABLE AL EXTREMISMO”. Diario La Esfera», Caracas, 31 de mayo de 1961, AGA, 54/11875, PE, Oficina de Información Diplomática, n. 756. 
ocasiones puntales no dudó en censurar ciertas actuaciones de los diferentes grupos informativos. ${ }^{114}$

Siguiendo esta tendencia, en un documento de 1962, el encargado de negocios hacía llegar a Madrid informaciones acerca de actos censura ejercidos contra diarios de una filiación no extremadamente radical. ${ }^{15}$ Uno de los diarios que sería objeto de censura sería El Universal, ${ }^{116}$ quien curiosamente será definido en otro documento como un diario «ultra burgués». ${ }^{117}$ La embajada incluía la línea editorial de cada periódico en casi cualquier documento, ya que les ayudaba a ordenar su cosmovisión del entramado político-mediático. Las noticias que publicaban los diarios y sus posicionamientos ideológicos recibían mucha atención, sobre todo si se les compara con otros medios de comunicación como la radio, que pasaba mucho más desapercibida. En esa cosmogonía mediática se encontraban, por una parte, los diarios cercanos a la URD, Dominguito y Clarín, que experimentaron situaciones de censura, ${ }^{118}$ pero también otro tipo de diarios más cercanos al gobierno o a la izquierda radical.

La diplomacia española identificaba bien a los medios que rechazaban el modelo comunista, entre los que identificaba a algunos de centro-derecha y también a los de la Cadena Capriles. ${ }^{119}$ El diario La Esfera, uno de los que más es recortado y enviado a Madrid pertenecía a dicha Cadena. Resulta curioso como utilizaban más la información aparecida en este que la que se publicaba en las hojas de La Religión, quizás el diario más cercano al pensamiento copeyano o democristiano. En el punto más cercano al posicionamiento gubernamental se encontraba La República, al cual consideraban el «órgano oficioso del gobierno». ${ }^{120}$

La otra cara de la moneda la ocupaban los grupos mediáticos o publicaciones que la diplomacia española consideraba como extremistas. En el primer grupo se encontraban las publicaciones con un perfil relativamente izquierdista que la diplomacia española consideraba como radicales

114 Caballero, 2004, 366-340

115 «Quejas de la prensa venezolana contra la falta de libertad y censura impuesta por el gobierno», Caracas, 26 de julio de 1962, AGA, 54/11877, PE, n. 506.

116 Idem.

117 «Remite recortes prensa esta Capital referente últimos sucesos de Cuba», Caracas, $10 \mathrm{de}$ mayo de 1961, AGA, 54/11876, PE, Oficina de Información Diplomática, n. 665.

118 «Quejas de la prensa...», 26 de julio de 1962, AGA, 54/11877, PE, n. 506.

119 «Tensión relaciones Cuba-Venezuela», 8 de noviembre de 1960, AGA, 54/11868, PE, n. 1147 , ff. 1-2.

120 «Visita a Venezuela del Presidente de Bolivia, Paz Estensoro», Caracas, 26 de septiembre de 1962, AGA, 54/11877-04, PE, n. 677, f. 2. 
o extremistas. En el segundo, aquellas publicaciones que hacían proselitismo expreso de puntos de vista relacionados con el marxismo. Entre los primeros destacaba El Nacional, probablemente el diario más importante y el cual siempre iba acompañado en la documentación del epíteto «filocomunista». ${ }^{121}$ El Nacional no dudará en publicar informaciones comprometidas para el gobierno o con un punto de vista izquierdista, como por ejemplo las declaraciones del sacerdote de Valera, las cuales escocieron mucho en la delegación española. No solo recibió epítetos de este tipo el diario en sí, sino también periodistas como su director Otero Silva, al que consideraban «de tendencia muy izquierdista». ${ }^{122} \mathrm{El}$ apelativo de extremista no solo lo recibió El Nacional y otros medios de comunicación izquierdista, también algunas asociaciones como la Asociación Venezolana de Periodistas (AVP) fue calificada de igual manera. ${ }^{123}$

A pesar de la situación de cierta censura, propiciada en parte por la constante suspensión de garantías constitucionales, se permitirá la publicación de revistas abiertamente comunistas, tanto internas como externas. Durante los primeros años de la década de los sesenta, no era complicado conseguir ejemplares de Unión Soviética, China ilustrada o Pekín Review en las calles de Caracas. Esta es una cuestión que sorprende de manera especial a las autoridades españolas. ${ }^{124}$ El proceso de radicalización de los partidos izquierdistas y, sobre todo, los enfrentamientos con el gobierno de Cuba, propiciaron la prohibición de la propaganda cubana a partir del día 2 de noviembre de 1960. No solo se prohibirán los diarios sino también los panfletos, así como el envío de otros materiales, entre los que podían encontrarse armas. ${ }^{125}$ Tanto las publicaciones del PCV como las del MIR, seguirían a posteriori los pasos de sus homólogas cubanas pero, como bien afirma la delegación española en Caracas, las publicaciones cubanas seguían circulando de manera informal. ${ }^{126}$

121 En algunos documentos llegó a ser definido como «filocomunista y ardiente partidario de la revolución cubana». Véase: «Designado nuevo Encargado de Negocios de Cuba en esta capital», Caracas, 7 de enero de 1961, AGA, 54/11868, PE, n. 18.

122 «Constitución Comité pro libertad Dominicana», Caracas, 29 de enero de 1959, AGA, 54/11867, PE, n. 48.

123 Idem.

124 «Ataques contra el Comunismo en la prensa venezolana», Caracas, 31 de diciembre de 1960, AGA, 54/11868, PE, n. 1501.

125 «Propaganda comunista cubana en Venezuela», Caracas, 7 de noviembre de 1960, AGA, 54/11868, PE, n. 1132. n. 1187

126 «Relaciones Cuba-Venezuela», Caracas, 19 de noviembre de 1960, AGA, 54/11868, PE, 


\section{Cuba y el Caribe: una cuestión de política interna}

La «cuestión cubana»y, en un sentido extenso, la problemática caribeña, nunca fueron percibidos como una cuestión totalmente diferenciada de la dinámica política interna de Venezuela. Esta realidad fue rápidamente percibida desde la legación española. Las cuestiones caribeñas tenían una relevancia considerable y ocupaba una parte nada desdeñable de la información que se enviaba desde Caracas a Madrid. Los acontecimientos que sucedían en la República Dominicana y en Cuba, eran considerados como una parte más de la propia dinámica política interna. Las connotaciones de la información que aporta la embajada se vinculan muy poco con la relación que Madrid tenía con los gobiernos de La Habana o Santo Domingo. Si bien con el primero la realidad muestra una dinámica de cordialidad que subyace durante gran parte del período inicial del modelo cubano, ${ }^{127}$ las informaciones que se aportan desde Caracas no perciben a Cuba como un aliado. El caso dominicano es menos acusado pero también existente, a pesar de las buenas relaciones intergubernamentales, ${ }^{128}$ las informaciones no se posicionarán en su favor.

La percepción que se tenía de Betancourt con respecto a las dos experiencias autoritarias del Caribe es que era un hombre decidido a romper con las dictaduras del Caribe y que jugaría las dos cartas (contra Castro y contra Trujillo) de manera simultánea con respecto a los diferentes socios que podían ver como enemigo a uno solo de los dos. ${ }^{129}$ Este juego a dos bandas no solo será la principal estrategia de actuación de la llamada Doctrina Betancourt, ${ }^{130}$ sino que será percibido por algunos de los personajes más importantes de la embajada durante esos años. Sin ir más lejos, el marqués de Saavedra definirá la clausura de la sede en Caracas de la agencia cubana Prensa Latina, como una como una «concesión» del gobierno venezolano a los EE. UU., ${ }^{131}$ motivado en parte por un cambio de posición de este con respecto a Trujillo. Además, para reforzar esta impresión en Madrid, el embajador español hará llegar voces importantes que también defiendan esta

127 De Paz Sánchez, 2001

128 Eiroa y Ferrero, 2016.

129 «Designado nuevo Encargado...», 7 de enero de 1961, AGA, 54/11868, PE, n. 18. «Postura de Venezuela ante ruptura colectiva de relaciones con Cuba», Caracas, 9 de enero de 1961, AGA, 54/11868, PE, n. 65.

130 Para un mayor desarrollo de la cuestión, pueden verse Romero, 2005 y Rodríguez, 2011.

131 «Remite recorte prensa El Nacional titulado: "Fue clausurada la Agencia Prensa Latina"», Caracas, 12 de mayo de 1961, AGA, 54/11876, PE, Oficina de Información Diplomática, n. 674. 
postura, como es el caso del embajador venezolano en Buenos Aires, quien respondió a una pregunta sobre la posible ruptura colectiva de las relaciones con Cuba aduciendo que «mientras no sea liquidada la dictadura de Rafael Leónidas Trujillo, Venezuela no tomará posición alguna en relación a los problemas políticos del Caribe». ${ }^{132}$

La Doctrina Betancourt buscaba la democratización de América Latina, por lo que no afectaba a España y no generaba grandes problemas al gobierno franquista, no así a algunos aliados. Betancourt promovió la democratización de la región a través del sistema interamericano, en primer lugar contra Trujillo, a quien calificó de «régimen despótico por violador de los derechos humanos», ${ }^{133}$ y quien fue defendido por algunos países como el Brasil de Kubitschek. La realidad es que muchos países no creían en el modelo que defendía el presidente venezolano, y otros países, como los EE. UU., solo creían a medias (en su vertiente anticomunista). La Doctrina era una herramienta de política exterior pero también interior. Que la cuestión dominicana estaba integrada en la sociedad venezolana fue una realidad que el propio Betancourt pudo experimentar cuando sufrió en sus propias carnes el intento de magnicidio de la Avenida de los Próceres. ${ }^{134}$ La diplomacia española sabía de la importancia de la República Dominicana para Venezuela. En sus informaciones hablaba de «Libertad dominicana» un programa en Radio Continente, en el que supuestamente se dedican a conspirar contra Trujillo y, entre otras cosas, enseñaban a la población a hacer bombas molotov. ${ }^{135}$ Otro de los acontecimientos de los que se informó a Madrid fue la conformación del Comité pro Libertad Dominicana. Este se había originado, según el personal de la embajada, por la influencia de la AVP, a la que ya hemos visto que consideraban extremista, y por la visita de Fidel Castro a Caracas. ${ }^{136}$ Lo masivo del apoyo y el soporte a la iniciativa de algunos personajes del ámbito católico, ya fuere de la jerarquía o de sectores periodísticos afines, no hizo demasiada gracia a la legación española, quien se congratuló de que el General López Contreras declinara participar, definiendo su actuación como «la única nota de ponderación y sensatez». ${ }^{137}$

132 «Postura de Venezuela ante ruptura...», 9 de enero de 1961. AGA, 54/11868, PE, n. 65.

133 Betancourt, 2007, 296.

134 Para ampliar, véase Mondolfi Gudat, 2013.

135 «Violencia de la radio en su propaganda política», Caracas, 30 de noviembre de 1959, AGA, 54/11855, Dirección General de PE, n. 605.

136 «Constitución Comité pro...», 29 de enero de 1959, AGA, 54/11867, PE, n. 48, f. 1.

137 Ibidem, ff. 2-3. 
Finalmente, el asesinato de Trujillo en mayo de 1961, acabaría con la mitad de los problemas caribeños de Betancourt, pero la intensidad del otro conflicto aumentaría. Cuando sobreviene el fin del trujillismo, las relaciones cubano-venezolanas se encontraban ya encaminadas hacia la ruptura. Muy atrás quedaban aquellas celebraciones en Caracas por la caída de Batista, en las que habían participado numerosos adecos como el mismo presidente electo, y del que había informado la embajada española en su momento. ${ }^{138}$

Las calles de Caracas pronto convirtieron la cuestión cubana en algo interno. Cualquier elemento de la dinámica bilateral o interna del país isleño recibía numerosa atención y así lo reflejaba la diplomacia española. Al ya preexistente apoyo fidelista en el país, que era notable, se unió una creciente comunidad de cubanos que habían huido de la Revolución. Dentro de ese ambiente efervescente, los actos pro y antifidelistas se solían suceder, ${ }^{139}$ creciendo cada vez más la conflictividad, no solo entre ambos grupos, sino también con sectores políticos netamente endógenos. Ocurrida la ruptura de las relaciones entre Venezuela y Cuba y entre el gobierno y los grupos de oposición radical cristalice, los exiliados anticastristas serán un objetivo político y sufrirán ataques. ${ }^{140}$

Esta efervescencia no solo afectará a Venezuela, sino también indirectamente a España. La legación española estará muy atenta e informará de actos en los que no solo se critican cuestiones nacionales o regionales, sino en los que se ataca la figura de Franco. ${ }^{141}$ No se puede obviar que Cuba ocupará un lugar importantísimo en la dinámica latinoamericana del franquismo. Una prueba notable de ello es el famoso incidente de Castro con el embajador Lojendio en La Habana, ${ }^{142}$ que acarreará mucho trabajo en el Ministerio de Asuntos Exteriores. Castiella tomará la cuestión como algo regional, no bilateral y dará órdenes de tantear y apaciguar la situación, no solo a su legación en Cuba, sino también en otros países de la región como

138 «Repercusión en Venezuela de la caída de Batista», Caracas, 2 de enero de 1959, AGA, 54/11867, PE, n. 1.

139 «Actos organizados por los exilados cubanos en Caracas», Caracas, 1 de agosto de 1959, AGA, 54/11877, PE, n. 508.

140 «Ataques a los Centros de exilados cubanos por comunistas armados», Caracas, 6 de noviembre de 1961, AGA, 54/11870, PE, n. 1218.

141 «Remite recorte El Universal de hoy conteniendo nota del movimiento estudiantil cubano en Venezuela», Caracas, 26 de noviembre de 1961, AGA, 54/11875, PE, Oficina de Información Diplomática, n. 1263.

142 Para un mayor desarrollo, véase De Paz Sánchez, 1999, 301-317. 
Venezuela. ${ }^{143}$ Está claro que la dinámica exterior cubano-venezolana en esta época tendrá muchos matices y que muchos serán captados por la legación española. Las primeras noticias de desencuentros entre ambos gobiernos no tardarán en ser transmitidas a Madrid, ${ }^{144}$ pero por cuestiones de diseño de la investigación y, sobre todo de espacio, no pueden ser abordadas en profundidad en este artículo. Lo que sí percibe la legación española es una relación directa entre la dinámica interior y la exterior. La cuestión cubana afectará a la realidad partidista y gubernamental. A finales de 1961 se haría efectiva una ruptura de relaciones diplomáticas que, en lugar de ser un punto y final en el conflicto, se convertirá en un punto y seguido. Aún así, la legación española en Caracas entenderá que la ruptura con Cuba se produce precisamente en esta fase debido a que Betancourt domina más las calles ${ }^{145}$ y tiene menos miedo a una reacción interna. En definitiva, ello solo supone una muestra más de que las vicisitudes políticas cubanas y las relaciones entre La Habana y Caracas constituían una realidad influyente de primera magnitud con respecto a la dinámica política interna.

\section{Conclusiones}

La Venezuela de los inicios del período democrático será un elemento cercano a la par que incierto para la España franquista y su entramado diplomático. La caída de un gobierno amigo y el triunfo de potenciales enemigos en las elecciones democráticas dejaban una situación de incertidumbre sobre unas relaciones que se habían hecho más importantes a raíz de la vasta red migratoria que se había desarrollado previamente. En medio de esa situación de incertidumbre, la diplomacia franquista va a comprender rápidamente que le interesa mantener vínculos con una Venezuela que está tan centrada en hacer sobrevivir a su régimen y en una política exterior profundamente pragmática, que no se embarcará en grandes reivindicaciones más allá de América. La voluntad pactista del gobierno y las consecuencias que ello tenía en forma de política exterior no maximalista por parte de los adecos, propició una relación de cordialidad.

143 Telegrama circular n. ${ }^{\circ}$ 4, Madrid, 26 de enero de 1960, AGA, 54/11865.

144 «Relaciones venezolano-cubanas», Caracas, 24 de agosto de 1959, AGA, 54/11867, Dirección General de PE, n. 362. Reservado.

145 «Tensión relaciones diplomáticas venezolano-cubanas», Caracas, 7 de noviembre de 1961, AGA, PE, n. 1224. 
Desde el punto de vista de la diplomacia franquista, tampoco hubo un exceso de beligerancia ante ciertas cuestiones. Castiella lo comprendió rápidamente y el cambio de embajador pudo estar propiciado por el posicionamiento del marqués de Saavedra con respecto a Valdés, mucho más abierto. En cierta medida, nuevas realidades traían consigo nuevas personalidades. En España había necesidad de reconocimiento y de normalidad, por ello propiciaron acuerdos en políticas como la migratoria y no se enfrentaron demasiado a un país y a un partido gobernante que siguieron siendo, muchos años después de la Guerra Civil en España, refugio de multitud de españoles que habían abandonando su país buscando, la mayoría, un futuro mejor, pero donde los españoles que se habían asentado por cuestiones políticas no eran escasos. El franquismo limitó al máximo las expresiones de protesta y repulsa ante las múltiples expresiones populares y grupales de antifranquismo en el ámbito público, que no solo eran permitidas por el gobierno, sino que, además, en cierta medida, también eran amparadas. Las fricciones debían ser evitadas y el objetivo era mantener las relaciones. Mucho menos habría un alineamiento explícito con otros gobiernos autoritarios amigos situados en la región. En ese punto, el primer gobierno venezolano diferenciaba entre las legítimas aspiraciones democráticas del pueblo español y la realpolitik de las relaciones bilaterales de cordialidad.

Desde el punto de vista de la legación española, se puede observar con total nitidez, cómo se produce un apoyo al gobierno presidido por Betancourt, una vez se confirma que no habrá ruptura de las relaciones. Para la legación española, la estabilidad moderada que supone la nueva democracia es positiva. Todo ello aun sin defender o sin entender, algunas de las características de una democracia formal, como puede ser la libertad de prensa. En la legación española saben que una salida por la derecha es imposible en el cambio de década (incluso podría ser contraproducente por un posible efecto péndulo), pero una salida por la izquierda revolucionaria sí que lo observan como una realidad más probable. En cierta medida, la embajada española entiende que la estabilidad, en ese punto de la situación, es igual a continuidad e, igualmente, a normalidad en cuanto a la continuidad de las relaciones bilaterales.

En definitiva, aunque entre el modelo de democracia que blasona la nueva Venezuela republicana y el marcado autoritarismo del franquismo de principios de los sesenta hay un mundo, tanto en ideología como en posicionamientos concretos, el pragmático reconocimiento se impondrá. Ante el temor del efecto contagio comunista propiciado desde Cuba o producido de manera endógena, y que dificultaría las relaciones, la nueva realidad se aceptará no 
de mala gana. La creencia en el pragmatismo de un Betancourt que había acabado repudiando su pasado comunista y la participación de los democristianos en el gobierno, aun estando situados a la izquierda que sus homónimos europeos, suponían una cierta garantía de que las relaciones al nivel de gobiernos, principal aspiración de la diplomacia franquista, se mantendrían.

Recibido, 5 de julio de 2020 Segunda versión, 1 de octubre de 2020

Aceptado, 5 de octubre de 2020

\section{Referencias bibliográficas}

Alexander, Robert J., The Venezuelan Democratic Revolution: A Profile of the Regime of Rómulo Betancourt, Nueva Jersey, Rutgers University Press, 1964.

Alexander, Robert J., El Partido Comunista de Venezuela, México D. F., Diana, 1971.

Betancourt, Rómulo, Antología política: vol. IV 1945-1948, Caracas, Fundación Rómulo Betancourt, 1990.

Betancourt, Rómulo, Antología política: vol. VII 1945-1948, Caracas, Fundación Rómulo Betancourt, 2007.

Bífano, José Luis, Luces entre sombras. La UCV, el CDCH y la investigación universitaria, Caracas, Universidad Central de Venezuela, 2008.

Buttó, Luis Alberto, «El golpismo se viste de blanco: insurrecciones navales contra la naciente democracia venezolana», Tiempo y espacio, 64, Caracas, 2015, 509-544.

Caballero, Manuel, Rómulo Betancourt, político de nación, Caracas, Alfadil/Fondo de Cultura Económica, 2004.

Campos Álvarez, Xosé Ramón, «La emigración gallega a Venezuela», tesis doctoral dirigida por Carlos Sixirei Paredes, Madrid, Universidad Complutense de Madrid, 2015.

Cañellas Más, Antonio, «La embajada española en Colombia: acción y proyectos para una política en Iberoamérica (1959-1962)», Revista de Indias, LXXVIII:272, Madrid, 2018, 289-320.

Capriles, Miguel Ángel, Memorias de la inconformidad, Caracas, [s. e.], 1973.

Cerrano, Carolina, «La política argentina mirada desde la España franquista. Un recorrido a través de la diplomacia y la prensa (1955-1976)», tesis doctoral dirigida por Álvaro Ferrary Ojeda, Pamplona, Universidad de Navarra, 2011.

Coppedge, Michael, «Venezuelan Parties and the Representation of the Elite Interests», en Middlebrook, Kevin J. (ed.), Conservative Parties, the Right, and Democracy in Latin America, Baltimore, Johns Hopkins University Press, 2000, 110-138. 
De Paz Sánchez, Manuel, Zona rebelde: La diplomacia española ante la Revolución Cubana (1957-1960), La Laguna, Centro de la Cultura Popular Canaria, 1997.

De Paz Sánchez, Manuel, Zona de Guerra. España y la Revolución Cubana (19601962), La Laguna, Centro de la Cultura Popular Canaria, 2001.

De Paz Sánchez, Manuel y Luis León, Ángel Dámaso, Entre la revolución y la utopía. Los anarquistas españoles ante Cuba y Venezuela (1958-1961), Islas Baleares, Calumnia, 2019.

Duverger, Maurice, Los partidos políticos, México D. F., Fondo de Cultura Económica, 1969.

Eiroa, Matilde y Ferrero, M. ${ }^{\text {a }}$ Dolores, «Rafael L. Trujillo y Francisco Franco: de los vínculos históricos a los compromisos coyunturales», Iberoamericana, XVI:61, Berlín, 2016, 149-170.

Escobedo Romero, Rafael, «La embajada en Washington de Antonio DíazCañabate (1962-1964): ¿una diplomacia para el aperturismo?», Historia y Política, 23, Madrid, 2010, 243-273.

Ewell, Judith, «The Extradition of Marcos Pérez Jiménez, 1959-1963: Practical Precedent for Enforcement of Administrative Honesty?», Journal of Latin American Studies, 9:2, Cambridge, 1977, 291-313.

Hall, Peter y Taylor, Rosemary, «Political Science and the Three New Institionalism», Political Studies, XLIV, Londres, 1996, 936-957.

Hernández González, Manuel, La emigración canaria a Venezuela, Santa Cruz de Tenerife, Ediciones Idea, 2007.

Irwin G., Domingo y Micett, Ingrid, Caudillos, militares y poder. Una historia del pretorianismo en Venezuela, Caracas, Universidad Católica Andrés Bello, 2008.

Langue, Frédérique, «Las relaciones civiles y militares en la historia reciente de Venezuela. Una historiografía en perspectiva», en Irwin G., Domingo; Buttó, Luis Alberto y Langue, Frédérique, Control civil y pretorianismo en Venezuela. Ilusiones y realidades históricas, Caracas, Universidad Pedagógica Experimental Libertador/Universidad Católica Andrés Bello, 2006, 187-218.

Linz, Juan José, La quiebra de las democracias, Madrid, Alianza Editorial, 1987.

Linz, Juan José y Stepan, Alfred, Breakdown of the Democratic Regimes, Baltimore, John Hopkins University, 1978.

Luis León, Ángel Dámaso, «Las relaciones hispano-venezolanas durante el Chavismo (1998-2013)», Historia Actual Online, 40, Cádiz, 2016, 45-58.

Luis León, Ángel Dámaso y De Paz Sánchez, Manuel, «Fidel Castro y Wolfgang Larrazábal (1958-1961). Dos transiciones, dos liderazgos, dos caminos», en Opatrný, Josef (coord.), Caribe hispano y Europa. Siglos XIX y XX: Dos siglos de relaciones, Praga, Universidad Carolina de Praga, 2018, 203-210.

Macías Martín, Francisco J., Cuba: crisis política, crisis económica y emigración (1920-1935): la visión de la diplomacia española, Tegueste, Baile del Sol, 2002.

Magallanes, Manuel Vicente, Los partidos políticos en la evolución histórica venezolana, Caracas, Editorial Mediterráneo, 1973. 
Marquès Sureda, Salomó y Martín Frechilla, Juan José, La labor educativa de los exiliados españoles en Venezuela, Caracas, Universidad Central de Venezuela, 2002.

Martín Frechilla, Juán José, Forja y crisol. La Universidad Central, Venezuela y los exiliados de la Guerra Civil española: 1936-1958, Caracas, Universidad Central de Venezuela, 2006.

Martz, John D., Acción Democrática. Evolution of a Modern Political Party in Venezuela, Nueva Jersey, Princeton University Press, 1966.

Mondolfi Gudat, Edgardo, «España y Venezuela en el siglo XX», Cuadernos hispanoamericanos, 592, Madrid, 1999, 67-76.

Mondolfi Gudat, Edgardo, El día del atentado. El frustrado magnicidio contra Rómulo Betancourt, Caracas, Alfa, 2013.

Mondolfi Gudat, Edgardo, Temporada de Golpes. Las insurrecciones militares contra Rómulo Betancourt, Caracas, Alfa, 2015.

Mondolfi Gudat, Edgardo, La insurrección anhelada. Guerrilla y violencia en la Venezuela de los sesenta, Caracas, Editorial Alfa, 2018.

Peters, Guy B., Institutional Theory in Political Science. The «New Institutionalism», Londres/Nueva York, Pinter Publisher, 1999.

Píriz Pérez, Emilio, Historia que compromete: UCAB: 60 años de servicio a Venezuela, Caracas, Universidad Católica Andrés Bello, 2014.

Robledo Limón, Ricardo, «El Partido Comunista de Venezuela. Sus tácticas políticas de 1964 a 1969», Foro Internacional, XI:4, México D. F., 1971, 531-551.

Rodríguez, Albor, Golpes de estado en Venezuela, 1945-1992: crónicas, testimonios, reportajes y fotografías de la época publicados en el diario El Nacional, Caracas, Los Libros de El Nacional, 2001.

Rodríguez, Frank, «La Doctrina Betancourt: entre el realismo y principismo político», Tiempo y espacio, 21:56, Caracas, 2011, 73-94.

Rodríguez Campos, William, «La Iglesia venezolana entre los siglos XIX-XX», Miscelánea Comillas: Revista de Ciencias Humanas y Sociales, 67-131, Madrid, 2009, 579-585.

Romero, Carlos Antonio, La relaciones entre Venezuela y la URSS: Diplomacia o Revolución, Caracas, Universidad Central de Venezuela, 1992.

Romero, María Teresa, Venezuela en defensa de la democracia, 1958-1998. El caso de la Doctrina Betancourt, Caracas, Fundación para la Cultura Urbana, 2005.

Sartori, Giovanni, Partidos y sistemas de partidos, Madrid, Alianza Editorial, 2005.

Urquijo García, José Ignacio, El movimiento obrero de Venezuela, Caracas, Organización Internacional del Trabajo/Universidad Católica Andrés Bello/Instituto de Altos Estudios Sindicales, 2004.

Velásquez, Ramón J., «Aspectos de la evolución política de Venezuela en el último medio siglo», en Velásques, Ramón J. et al., Venezuela moderna. Medio siglo de historia, 1926-1976, Caracas, Fundación Eugenio Mendoza. Editorial Ariel, 1979, 13-435. 